\title{
The impact of different spirometric definitions on the prevalence of airway obstruction and their association with respiratory symptoms
}

\author{
Howraman Meteran ${ }^{1}$, Martin R. Miller ${ }^{2}$, Simon Francis Thomsen ${ }^{3,4}$, \\ Kaare Christensen ${ }^{5}$, Torben Sigsgaard ${ }^{6}$ and Vibeke Backer ${ }^{1}$
}

Affiliations: ${ }^{1}$ Respiratory Research Unit, Bispebjerg University Hospital, Copenhagen, Denmark. ${ }^{2}$ Institute of Occupational and Environmental Medicine, University of Birmingham, Birmingham, UK. ${ }^{3}$ Dept of Dermatology, Bispebjerg University Hospital, Copenhagen, Denmark. ${ }^{4}$ Dept of Biomedical Sciences, University of Copenhagen, Copenhagen, Denmark. ${ }^{5}$ The Danish Twin Registry, Epidemiology, Institute of Public Health, University of Southern Denmark, Odense, Denmark. ${ }^{6}$ Dept of Public Health, Section of Environment Occupation and Health, Danish Ramazzini Centre, University of Aarhus, Aarhus, Denmark.

Correspondence: Howraman Meteran, Respiratory Research Unit, Bispebjerg University Hospital, Bispebjerg Bakke 23, Copenhagen 2400, Denmark. E-mail: hmeterandgmail.com

ABSTRACT The fixed ratio criterion of forced expiratory volume in $1 \mathrm{~s} /$ forced vital capacity $<0.70$ for diagnosing airway obstruction may overdiagnose the condition, particularly in the elderly, so the lower limit of normal (LLN) is recommended as the most appropriate criterion. Our aim was to compare LLN versus fixed ratio on the prevalence of chronic obstructive pulmonary disease (COPD) and examine the association between respiratory symptoms and airway obstruction defined by LLN and fixed ratio.

12449 twins aged $40-80$ years participated in a nationwide survey using the Danish Twin Registry. They completed a questionnaire, underwent clinical examination and recorded prebronchodilator spirometry. Individuals with self-reported asthma were excluded. Clinical COPD was defined by respiratory symptoms together with airway obstruction.

10329 individuals were included, with a mean \pm SD age of $58.4 \pm 9.6$ years and mean body mass index of $26.6 \pm 4.4 \mathrm{~kg} \cdot \mathrm{m}^{-2} ; 20 \%$ were current smokers, $37 \%$ former smokers and $43 \%$ never-smokers; and $48 \%$ were male. The prevalence of LLN airway obstruction (LLN-AO) and fixed ratio airway obstruction (FR-AO) was $5.6 \%$ and $18.0 \%$, respectively $(\mathrm{p}<0.001)$. Overall, $26 \%$ reported current respiratory symptoms, but $50 \%$ of those with LLN-AO had respiratory symptoms compared to $39 \%$ with FR-AO, $<<0.001$. The prevalence of clinical LLN-COPD and fixed ratio COPD was $2.6 \%$ and $6.3 \%$, respectively $(p<0.001)$. Individuals with LLN-AO had a significantly higher probability of reporting respiratory symptoms compared with both healthy individuals and FR-AO when adjusted for sex, age and ever-smoking.

The use of fixed ratio more than doubled the prevalence of clinical COPD compared with LLN, this being more pronounced with increased age, and identified subjects with a lower prevalence of respiratory symptoms than LLN-AO.

@ERSpublications

Prevalence of airway obstruction in a nationwide twin population http://ow.ly/x4QR30g1rId

Cite this article as: Meteran H, Miller MR, Thomsen SF, et al. The impact of different spirometric definitions on the prevalence of airway obstruction and their association with respiratory symptoms. ERJ Open Res 2017; 3: 00110-2017 [https://doi.org/10.1183/23120541.00110-2017].

This article has supplementary material available from openres.ersjournals.com

Received: Sept 062017 | Accepted after revision: Oct 052017

Conflict of interest: None declared

Copyright $\odot$ ERS 2017. This article is open access and distributed under the terms of the Creative Commons Attribution Non-Commercial Licence 4.0. 


\section{Introduction}

Chronic obstructive pulmonary disease (COPD) poses a challenge for public health worldwide and has been estimated to be the third leading cause of death in 2030 [1]. The Global Initiative for Chronic Obstructive Lung Disease (GOLD) recommends the use of a fixed postbronchodilator forced expiratory volume in $1 \mathrm{~s}(\mathrm{FEV} 1) /$ forced vital capacity (FVC) ratio of $<0.7$ for the diagnosis of COPD [2]. This method has been criticised, as it does not take the age-dependent decline in FEV1/FVC into account [3]. Furthermore, the fixed ratio has been shown to both underdiagnose airway obstruction (particularly in young females) and overdiagnose it (particularly in older males) [3-10], with the latter group posing a great challenge, as older patients with shortness of breath may have nonpulmonary causes for their dyspnoea [11-13].

Since 2005 the American Thoracic Society (ATS) and the European Respiratory Society (ERS) have recommended the use of lower limit of normal (LLN) for FEV1/FVC to define airway obstruction as a $\mathrm{z}$-score of $<-1.645$ in studies with an a priori probability of abnormality and a $\mathrm{z}$-score of $<-1.96$ in epidemiological studies $[14,15]$. There is no consensus in the literature on the prevalence of airway obstruction defined by the different spirometric criteria and varying estimates have been reported for both the fixed ratio and LLN $[11,16-22]$.

The Danish Twin Registry and collaborators from different research units conducted a large population-based survey of randomly selected adult twins with various aims. For this study we used these data to examine the impact of the spirometric criteria on the prevalence of airway obstruction and to look at the association between respiratory symptoms and fixed ratio airway obstruction (FR-AO) and LLN airway obstruction (LLN-AO).

\section{Methods}

Study participants

All individuals included in this study participated in the Infrastructure Initiative 2008-2011, which is a nationwide umbrella project of Danish twin individuals born 1931-1969. The clinical examinations took place in the three largest cities in Denmark: Copenhagen, Aarhus and Odense [23]. The population for the current study is based on two cohorts from middle-aged Danish twins (MADT) from the Danish twin register, consisting of 2402 individuals born 1931-1952, and a further 10281 individuals born 1931-1969 (MIDT). The participation rate was $62 \%$ for the MADT cohort and about $40 \%$ for the MIDT cohort. Questionnaire data were available for 12449 individuals and lung function data were available for 11219 (90\%) individuals. Participants with self-reported asthma were excluded ( $n=991)$, leaving 11458 individuals with questionnaire data; among these, lung function data were available for 10329 individuals. Only individuals with questionnaire and lung function data were included, and thus 10329 individuals were included in the analyses.

\section{Questionnaire data}

The participants completed a questionnaire at home, including questions on lifestyle factors, self-reported physician-diagnosed diseases and respiratory symptoms, and brought the questionnaire to the clinical examination. This was arranged to make the visit less time-consuming and ensure that the reported data were not influenced by the presence of a physician or nurse. Respiratory symptoms included shortness of breath at rest or during exercise, cough, chronic bronchitis (cough and sputum in $\geqslant 3$ months in two consecutive years), nocturnal awakening due to shortness of breath and chest tightness.

\section{Smoking}

The participants were asked about smoking habits in terms of daily units smoked and duration of smoking in years. Data were categorised into current, former and never-smokers. Pack-year exposure was calculated as the average number of cigarettes smoked per day/20 $\times$ number of years smoked.

\section{Clinical examination}

Anthropometry

Height was measured twice with the participant standing in an upright position wearing no shoes, heels together and head in the Frankfort position using a stadiometer and the average was recorded. Weight was measured using an electronic scale (Soehnle, Backnang, Germany) with the participant wearing light clothing.

\section{Spirometry and definition of airway obstruction}

Lung function testing was performed using a Spiroson-AS ultrasonic flowmeter (ndd, Zurich, Switzerland), which was calibrated prior to testing and with the participant in an upright sitting position wearing a nose clip with at least three acceptable and two reproducible measurements according to ARS/ERS guidelines for spirometry [24]. The Global Lung Initiative (GLI) 2012 reference values were used for FEV1, FVC and 
FEV1/FVC ratio [15]. The LLN-AO was defined in cases of an FEV1/FVC ratio <LLN corresponding to the 2.5th centile (LLN 2.5\%, z-score -1.96), as recommended for epidemiological studies [15], while the FR-AO was defined in cases of an FEV1/FVC ratio $<0.7$ [2]. For the sake of comparison, we distinguished between nonreversible airway obstruction (spirometrically defined) and clinical COPD (nonreversible airway obstruction plus respiratory symptoms), the latter as recommend by the ATS/ERS guidelines [14]. In the assessment of the severity of airway obstruction we used the GOLD guidelines and the ERS/ATS 2005 grading system, in which a proposal for a new grading system is included [25]. An attempt to reduce the misclassification of airway obstruction when using fixed FEV1/FVC ratio $<0.7$ is the " $65 / 65$ " model, in which a fixed ratio of 0.7 is used for individuals aged $<65$ years and a fixed ratio of 0.65 is used for individuals aged $>65$ years, as suggested in the Swedish COPD guidelines [26].

For the baseline characteristics described in table 1 we distinguished between individuals with FR-AO only $\left(0.7>\mathrm{FEV}_{1} / \mathrm{FVC}>\mathrm{LLN}\right)$ and those with LLN-AO, whereas FR-AO in all other tables and figures refer to those with $\mathrm{FEV} 1 / \mathrm{FVC}<\mathrm{LLN}$.

\section{Zygosity assessment}

In same-sex twin pairs zygosity was determined based on a questionnaire method using four questions on similarity. The overall misclassification rate using this method is as low as $4 \%$ when compared with genetic marker analysis, and is thus regarded as a valid classification method [27].

\section{Statistical analysis}

Chi-squared tests and t-tests were used to compare the baseline characteristics in the healthy, LLN-AO and FR-AO populations. Multiple logistic regressions were used to compare the risk of respiratory symptoms in the two predefined populations with airway obstruction. Venn diagrams were created to illustrate the overlap between the population with respiratory symptoms and the subgroups with airway obstruction classified by different spirometric definitions. A categorical age variable was defined and the study sample was divided into eight age groups: 40-44, 45-49, 50-54, 55-59, 60-64, 65-65, 70-74 and 75-80 years. Data were analysed using the statistical package Stata 14.0 (StataCorp, College Station, TX, USA).

One assumption in regression analyses is that data are uncorrelated, and since data within a twin pair are correlated, the CLUSTER option in Stata was added to the analyses, thereby ensuring this assumption was fulfilled.

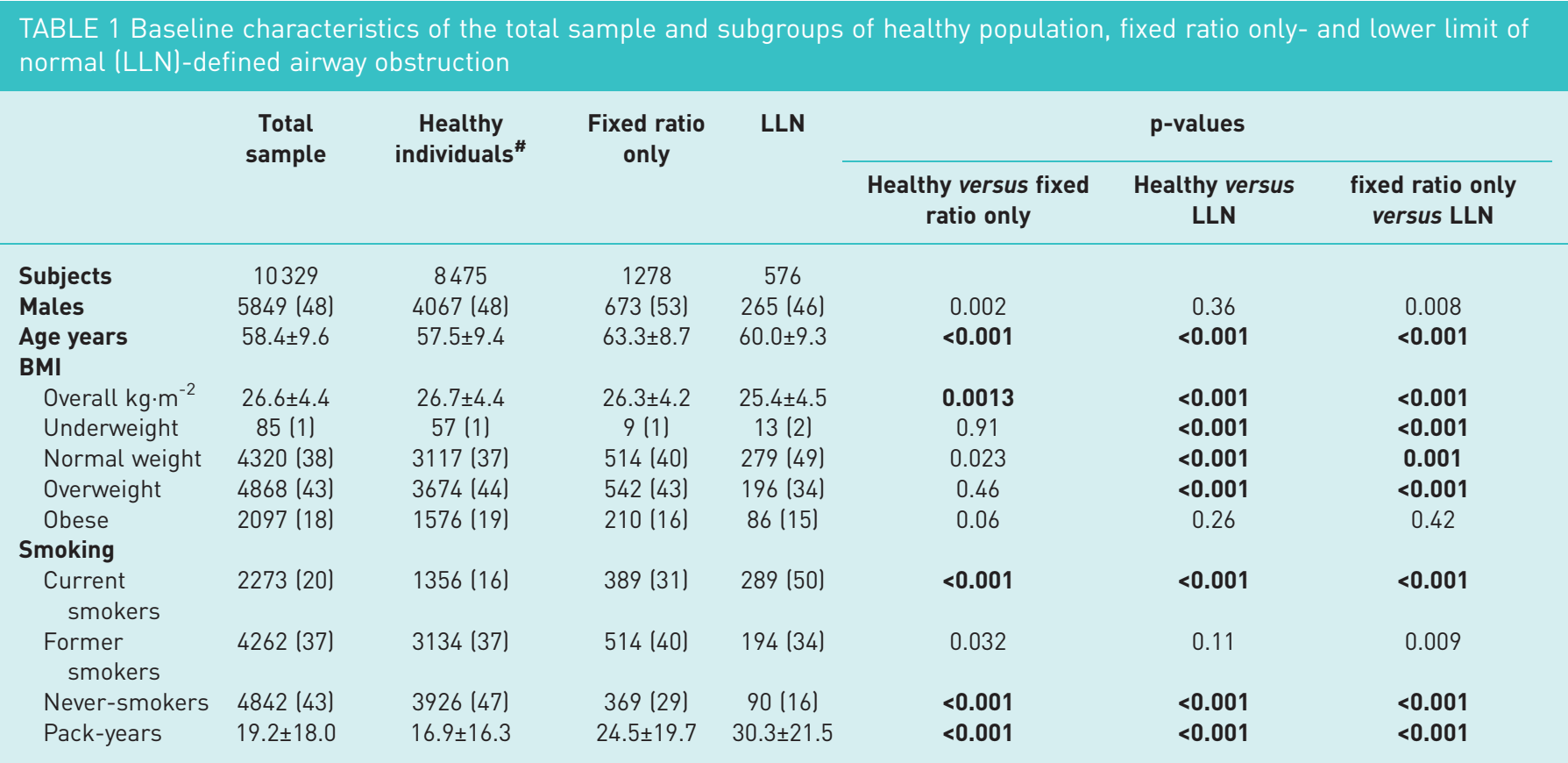

Data are presented as $\mathrm{n}, \mathrm{n}(\%)$ or mean $\pm \mathrm{SD}$, unless otherwise stated. BMI: body mass index. \# : individuals who had completed spirometry without fixed ratio airway obstruction (FR-AO) nor LLN-AO. The percentages are for available data and not the total number. $p$-values $<0.0015$ are emphasised in bold, as they meet significance after Bonferroni correction for multiple comparisons. 


\section{Results}

Table 1 presents the demographics for the 10329 individuals who had data available for analysis. Their mean \pm SD age was $58.4 \pm 9.6$ years, body mass index was $26.6 \pm 4.4 \mathrm{~kg} \cdot \mathrm{m}^{-2}$ and $48 \%$ were male. There was a significant difference in age between the three subgroups, with the healthy population being the youngest (57.5 \pm 9.4 years), followed by LLN-AO subjects (60.0 \pm 9.3 years) and FR-AO subjects were oldest $(63.3 \pm 8.7$ years $)(p<0.001)$. The proportion of current smokers differed significantly between the three subgroups, being $16 \%$ for healthy individuals, $31 \%$ for FR-AO only and $50 \%$ for LLN-AO ( $<<0.001)$.

In the total sample, $26 \%$ reported respiratory symptoms and the prevalence of airway obstruction among those with lung function data $(n=10329)$ was $18.0 \%$ and $5.6 \%$ defined by fixed ratio and LLN, respectively $(\mathrm{p}<0.001)$. Significantly more of the individuals with LLN-AO had respiratory symptoms compared with the individuals with FR-AO (50\% versus 39\%, $\mathrm{p}<0.0001)$ (figure 1). The prevalence of clinical COPD was $2.6 \%$ and $6.3 \%$ when using the LLN and fixed ratio, respectively $(\mathrm{p}<0.001)$, while the prevalence of self-reported physician-diagnosed COPD (PD-COPD) was $1.9 \%$. There was a greater overlap between PD-COPD and LLN-COPD than between PD-COPD and FR-COPD (27\% versus $16 \%, \mathrm{p}<0.001)$ (figure 2 ).

All individuals with LLN-AO also had FR-AO, but not vice versa. Figure 3a shows the distribution of FEV1/FVC according to age in the whole population. The red dots represent those individuals with LLN-AO and the yellow dots represent individuals with FR-AO, but above LLN. The figure shows that the use of fixed ratio results in an overestimation of airway obstruction across all ages, but predominantly in the oldest age group. Figure $3 \mathrm{~b}$ shows the effect of the 65/65 model, which reduces but does not eliminate the overestimation.

The difference in prevalence of FR-AO and LLN-AO increased with age. While the difference in prevalence was $5.3 \%$ ( $8.0 \%$ versus 3.3 , respectively) in the youngest age group ( $40-44$ years), the difference was $30.4 \%$ (38.2\% versus $7.8 \%$, respectively) in the oldest age group (75-80 years). The prevalence of FR-AO ranged from $8.0 \%$ in the youngest group ( $40-44$ years) to $38.2 \%$ in the oldest group (75-80 years), whereas the prevalence of LLN-AO was $<10 \%$ for all age groups (figure 4 ).

The association between respiratory symptoms and FR-AO and LLN-AO was assessed in multiple logistic regressions adjusted for age, sex and ever-smoking (table 2). When compared to healthy individuals, both groups with airway obstruction had a significantly higher risk of reporting respiratory symptoms (model $1 ; \mathrm{p}<0.001$ ). In another analysis (model 2), comparing the groups $\mathrm{FR}-\mathrm{AO}^{+} \mathrm{LLN}^{-\mathrm{AO}^{-}}$

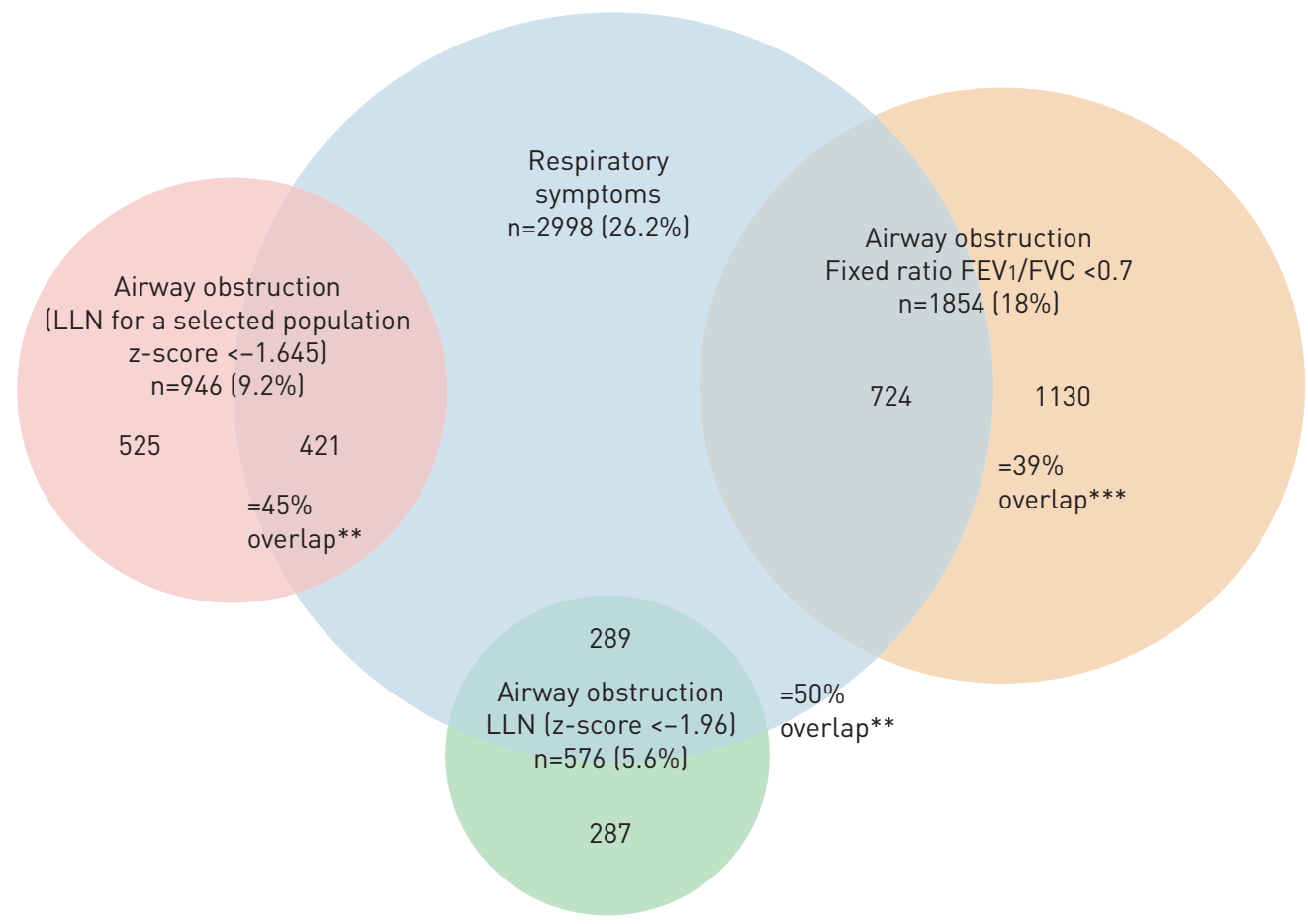

FIGURE 1 Venn diagram showing the overlap between the various spirometric definitions of airway obstruction and respiratory symptoms. ${ }^{* *}: p<0.01$ for difference between lower limit of normal (LLN) (for selected population) versus fixed ratio; ${ }^{* * *}$ : $p<0.001$ for LLN versus fixed ratio. 


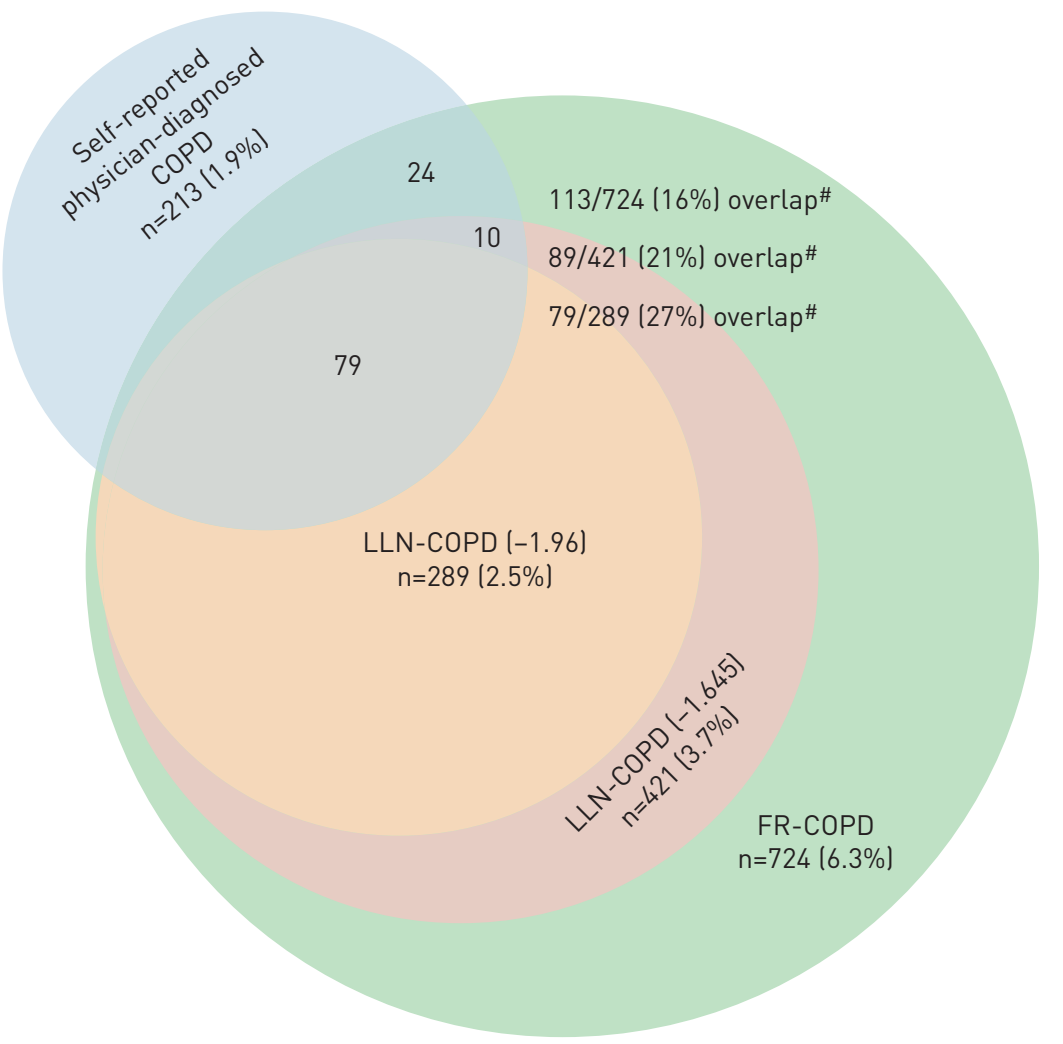

FIGURE 2 Venn diagram showing the overlap between the various chronic obstructive pulmonary disease (COPD) diagnoses: self-reported physician-diagnosed, fixed ratio (FR) and lower limit of normal (LLN). \#: $p$-values $<0.001$ for the difference in overlap between FR-COPD and LLN $(-1.96)$ and 0.02 for the difference in overlap between FR-COPD and LLN $(-1.645)$.

versus $\mathrm{FR}-\mathrm{AO}^{+} / \mathrm{LLN}-\mathrm{AO}^{+}$, we found that those with $\mathrm{LLN}-\mathrm{AO}$ had a significantly higher risk of reporting respiratory symptoms compared with those with FR-AO only.

Multivariate logistic regression analyses comparing the risk of respiratory symptoms and the various definitions of airway obstruction in monozygotic twins versus dizygotic twins showed no difference except

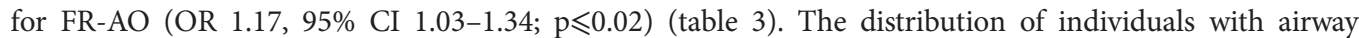
obstruction based on severity according to the GOLD guidelines, the ERS/ATS 2005 guidelines and the proposed staging system from QuANJER et al. [25] are shown in table 4. The proportion of individuals with respiratory symptoms in the different stages for each system was calculated and there was a significant difference in symptom prevalence between the staging by GOLD, the ERS/ATS 2005 and the proposal from QUANJER et al. in those individuals with mild and moderate airway obstruction. Allowing for GOLD having fewer stages, the moderate and moderately severe staging for the other two systems were aggregated and the symptom prevalence was $50 \%$ in moderate GOLD versus $59 \%$ and $63 \%$ in the ATS/ERS and QUANJER et al. staging systems, respectively. GOLD identified fewer subjects in the worst category than the other systems, and these subjects had fewer respiratory symptoms.

\section{Sensitivity analyses}

To explore the data further, we performed a number of sensitivity analyses. First, we estimated the prevalence of airway obstruction when using the LLN with a $\mathrm{z}$-score of -1.645 , as appropriate for patient-related data rather than population survey data. The prevalence of airway obstruction then increased from $6.6 \%$ to $9.2 \%$. In this case, the prevalence of FR-AO was still significantly higher, $(18.0 \%$ versus $9.2 \%, \mathrm{p}=0.001$ ). Likewise, the prevalence of clinical COPD increased from $2.5 \%$ to $3.8 \%$ and was still significantly lower than FR-COPD $(6.3 \%, \mathrm{p}<0.001)$. Second, we observed no sex differences in prevalence of LLN-AO and LLN-COPD, whereas a higher prevalence of FR-AO and FR-COPD was observed among males compared with females ( $18.7 \%$ versus $17.2 \%, \mathrm{p}=0.04$ and $6.9 \%$ versus $5.9 \%, \mathrm{p}=0.04$, respectively). Third, we defined FR-AO based on the 65/65 model. The prevalence of FR-AO then decreased from $18.0 \%$ to $14.3 \%$, but the overdiagnosis of airway obstruction in the oldest age group of the population was still present. Last, we applied the same analyses as presented in tables 1, 2 and 4, defining the LLN as a z-score 

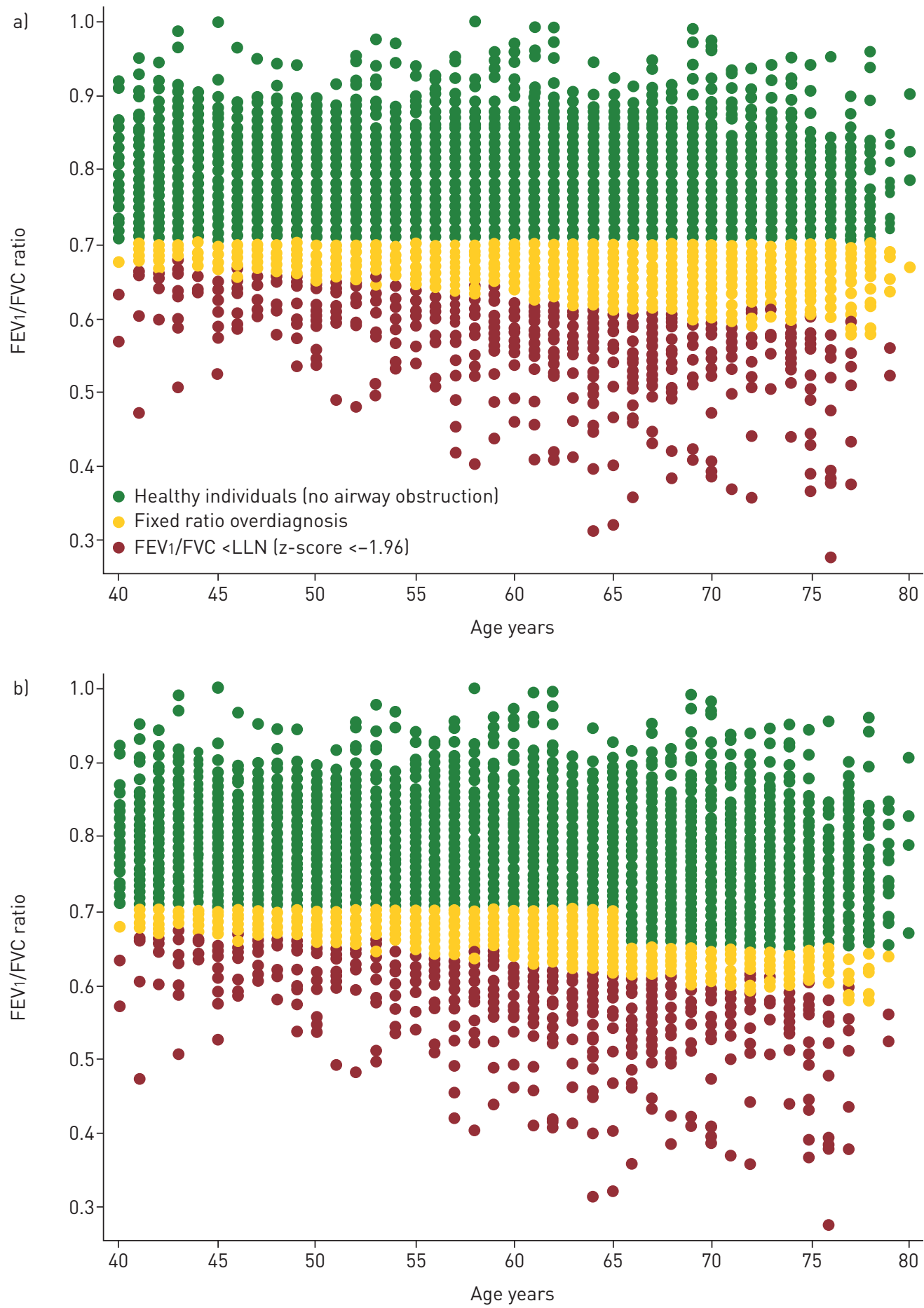

FIGURE 3 a) Forced expiratory volume in $1 \mathrm{~s}$ (FEV 1 )/forced vital capacity (FVC) ratio as a function of age showing individuals with FEV1/FVC ratio less than the lower limit of normal (LLN) (z-score <-1.96) and potentially overdiagnosed individuals with the use of the fixed ratio; b) the proportion of potentially overdiagnosed patients is reduced with the introduction of the $65 / 65$ model, but overdiagnosis is still present.

for FEV1/FVC-ratio <-1.645 for the sake of comparison with other studies. These analyses are shown in online supplementary tables $1 \mathrm{~S}, 2 \mathrm{~S}$ and $3 \mathrm{~S}$, respectively.

\section{Discussion}

In this random population-based study of adult twins, we found a higher prevalence of airway obstruction when using the fixed $\mathrm{FEV} 1 / \mathrm{FVC}$ ratio $<0.7$ compared with FEV1/FVC ratio <LLN, which agrees with 
FIGURE 4 Prevalence of airway obstruction in a random population assessed by fixed ratio and lower limit of normal (LLN) stratified by age. Data are presented as odds ratio $(95 \% \mathrm{Cl})$.

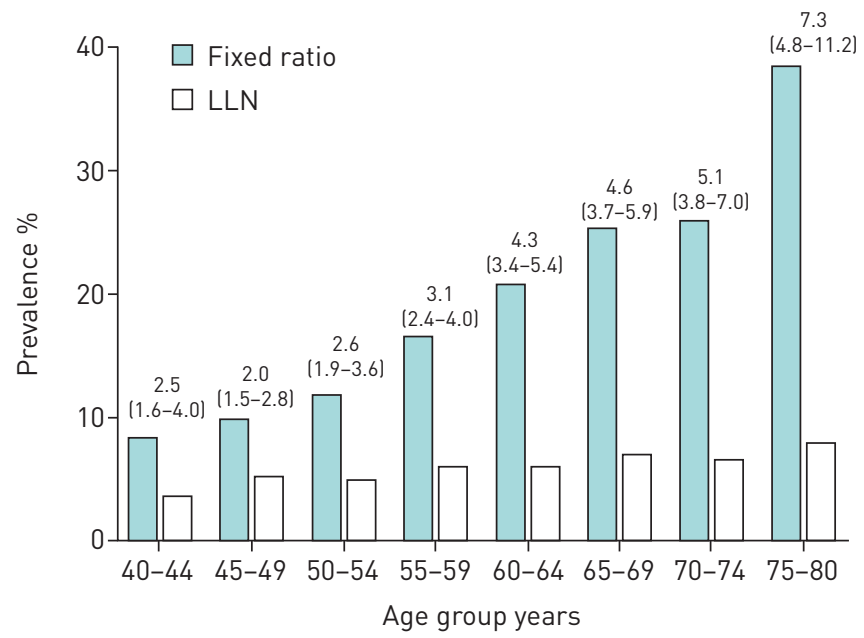

previous findings of the prevalence of FR-AO ranging from $10.9 \%$ to $21.3 \%$ [21, 22], the LLN-AO $(5.9-14.7 \%)[21,22]$ and self-reported COPD $(4.6-10.6 \%)[21,28]$. In addition, we found that the difference in prevalence was more pronounced with increasing age, which is in line with other studies comparing the impact of different spirometric definitions $[11,20]$. Results from a Canadian study by vaN DIJK et al. [11] are comparable to ours, suggesting the highest prevalence of airway obstruction in the oldest age groups. However, a study by KARRASCH et al. [20] found the highest prevalence of LLN-AO in the youngest age group (40-44 years) and the lowest among the oldest age group ( $>84$ years), which is the exact opposite of our findings; however, this study did not include symptoms in their diagnostic criteria.

In the present study we distinguished between the presence of airway obstruction only from clinical COPD, which requires nonreversible airway obstruction and symptoms. When we compared clinical COPD by fixed ratio and by LLN we found the highest prevalence was FR-COPD (6.3\%), followed by LLN-COPD (2.5\%), and the lowest for self-reported PD-COPD (1.9\%). Comparison of results with other workers is complicated by the varying methodology and different definitions used in research and these are an obvious explanation for the varying prevalence estimates. The case and disease definitions are not always described systematically in the studies and make comparisons across studies uncertain [20, 21].

TABLE 2 Associations between clinical outcomes and airway obstruction defined by fixed ratio (FR) and lower limit of normal (LLN) and symptoms

Healthy individuals
Model 1

Airway obstruction

Fixed ratio
LLN
Model 2

Airway obstruction

$\mathrm{FR}^{+} / \mathrm{LLN}^{-}$(n=1278) (ref.)

versus

$\mathrm{FR}^{+/} \mathrm{LLN}^{+}(\mathrm{n}=576)$

Ref. (\%) versus LLN (\%)

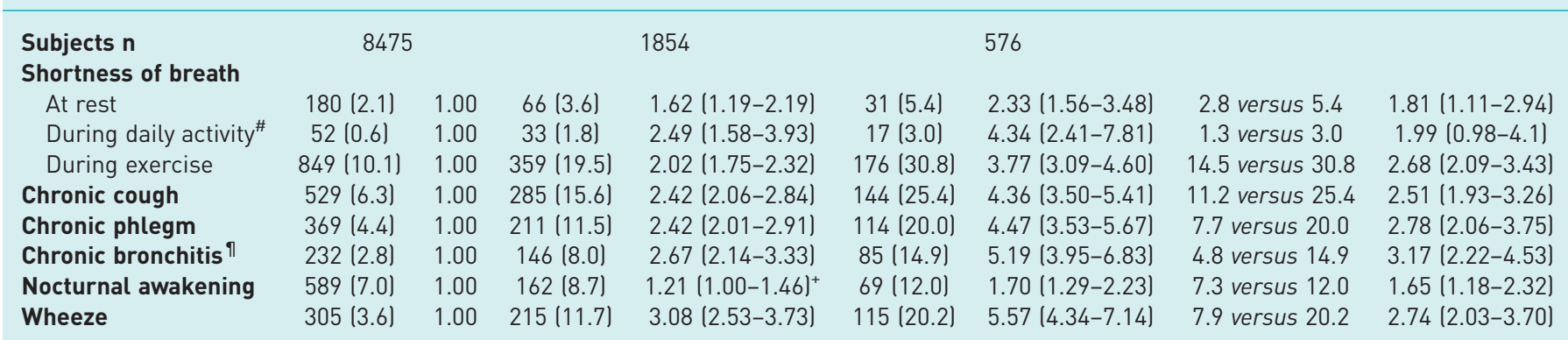

Data are presented as $\mathrm{n}(\%)$ and odds ratio $(95 \% \mathrm{CI})$, unless otherwise stated. Multiple logistic regression analysis adjusted for age las a dichotomous variable dividing the study sample at $<60$ years and $\geqslant 60$ years, sex, ever-smoking and body mass index. " : cleaning and dressing; ๆ: defined according to American Thoracic Society/European Respiratory Society guidelines; ${ }^{+}: \mathrm{p}$-value $=0.044$. 


\begin{tabular}{|c|c|c|c|c|c|}
\hline & \multicolumn{2}{|c|}{ Monozygotic twins } & \multicolumn{3}{|c|}{ Dizygotic twins } \\
\hline & Subjects & Reference & Subjects & Crude OR & Adjusted OR \\
\hline \multicolumn{6}{|l|}{ Respiratory symptoms } \\
\hline \multicolumn{6}{|l|}{ Shortness of breath } \\
\hline at rest & $58(2.4)$ & 1.00 & $211(2.5)$ & $1.04(0.78-1.41)$ & $1.03(0.76-1.38)$ \\
\hline during daily activities ${ }^{\text {I }}$ & 25 (1.0) & 1.00 & 73 (0.9) & $0.84(0.52-1.34)$ & $0.77(0.49-1.23)$ \\
\hline during exercise & 292 (11.8) & 1.00 & $1019(11.9)$ & $1.00(0.87-1.16)$ & $0.96(0.83-1.11)$ \\
\hline Chronic cough & $190(7.8)$ & 1.00 & $684(8.0)$ & $1.03(0.87-1.23)$ & $0.99(0.83-1.18)$ \\
\hline Chronic phlegm & $130(5.3)$ & 1.00 & 507 (5.9) & $1.13(0.92-1.39)$ & $1.08(0.88-1.34)$ \\
\hline Chronic bronchitis $^{+}$ & 83 (3.4) & 1.00 & 328 (3.8) & $1.14(0.89-1.48)$ & $1.11(0.86-1.43)$ \\
\hline Nocturnal awakening & $194(7.8)$ & 1.00 & $606(7.0)$ & $0.89(0.75-1.06)$ & $0.87(0.73-1.04)$ \\
\hline Wheeze & 131 (5.3) & 1.00 & 450 (5.2) & $0.98(0.80-1.21)$ & $0.95(0.78-1.18)$ \\
\hline \multicolumn{6}{|l|}{ Airway obstruction } \\
\hline $\mathrm{FR}$ & 338 (15.2) & 1.00 & 1470 (18.8) & $1.29(1.12-1.49)$ & $1.18(1.02-1.37)$ \\
\hline LLN & $109(4.9)$ & 1.00 & 451 (5.77) & $1.19(0.95-1.49)$ & $1.14(0.91-1.43)$ \\
\hline \multicolumn{6}{|l|}{ Clinical COPD } \\
\hline FR-AO + symptoms & $130(5.2)$ & 1.00 & $575(6.6)$ & $1.29(1.05-1.59)$ & $1.17(0.95-1.44)$ \\
\hline LLN-AO + symptoms & $59(2.4)$ & 1.00 & $218(2.5)$ & $1.06(0.78-1.44)$ & $0.99(0.73-1.34)$ \\
\hline \multicolumn{6}{|c|}{$\begin{array}{l}\text { Data are presented as } \mathrm{n}(\%) \text { or odds ratio (OR) (95\% CI). FR: fixed ratio; LLN: lower limit of normal; COPD: } \\
\text { chronic obstructive pulmonary disease. \#: multiple logistic regression analysis adjusted for age las a } \\
\text { dichotomous variable dividing the study sample at }<60 \text { years and } \geqslant 60 \text { years), sex and ever-smoking; } \\
\text { १: cleaning, cooking and dressing; }{ }^{+} \text {: defined according to American Thoracic Society/European Respiratory } \\
\text { Society guidelines. }\end{array}$} \\
\hline
\end{tabular}

Here, we have analysed data according to the recent recommendations for epidemiological studies from ERS/ATS by defining the LLN as a $z$-score $<-1.96$ for FEV1/FVC ratio [15]. However, for the sake of comparison we estimated the prevalence of airway obstruction with a LLN defined as a $\mathrm{z}$-score $<-1.645$ for FEV1/FVC. This resulted in a higher prevalence of airway obstruction (from $5.6 \%$ to $9.2 \%$ ), but which was still significantly lower than the prevalence of FR-AO.

Several studies have reported that the use of LLN compared with fixed ratio results in underdiagnosis in young individuals and overdiagnosis in the elderly [19,29-31]. This study showed no underdiagnosis in the youngest group, but substantial overdiagnosis was present across all age groups, and was predominant in the elderly. However, when we defined the LLN as a $\mathrm{z}$-score $<-1.645$, four young individuals were underdiagnosed and 912 mainly older subjects were overdiagnosed. The poor overlap between those with respiratory symptoms and those with either spirometric criteria could suggest that respiratory symptoms are not especially related to airway obstruction, although the overlap was significantly greater in the group with LLN-AO. The importance of labelling the patients correctly was evident in another Danish study showing that the high mortality in those subjects with GOLD classification group B (who have minimal

TABLE 4 Severity of airway obstruction according to different staging systems

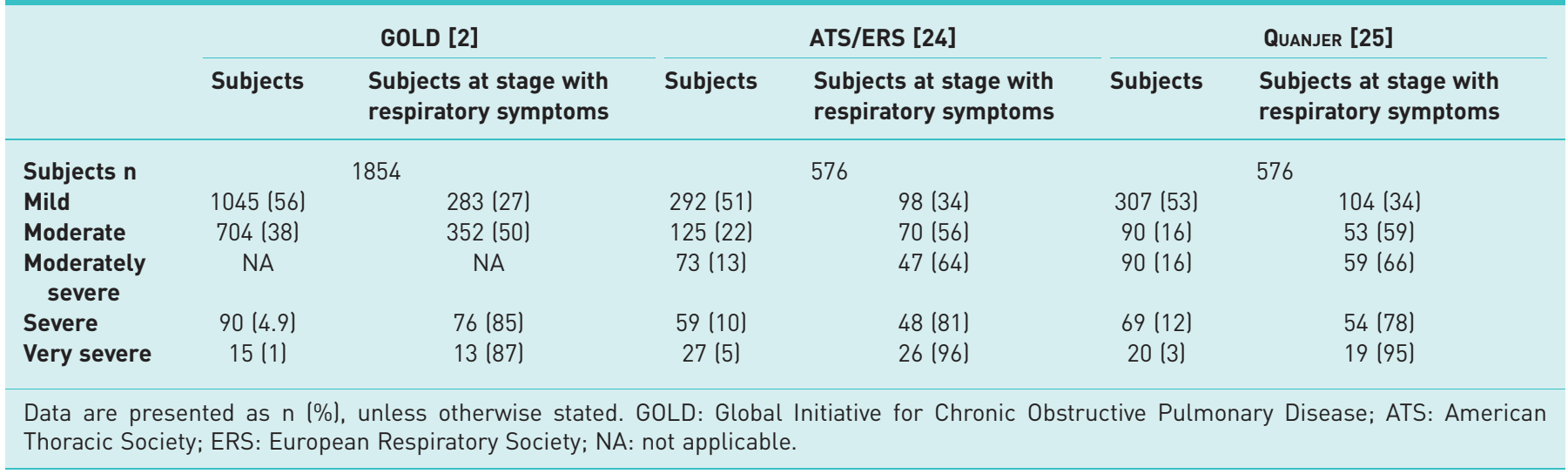


airflow limitation, but experience symptoms) could be due to overlooked heart disease [13]. Comparison between the different staging systems showed that a significantly higher proportion of individuals with mild to moderate airway obstruction reported respiratory symptoms when graded either according to ATS/ ERS guidelines or the proposal from QUANJER et al. [25] as compared to GOLD staging.

The multivariate logistic regression analyses showed that the risk of respiratory symptoms was increased in individuals with FR-AO compared with healthy individuals but this was seen to a greater extent in individuals with LLN-AO. This was evident in a further analysis comparing individuals with both FR-AO and LLN-AO with those with only FR-AO, suggesting that the use of LLN will result in a better identification of individuals with characteristic symptoms of COPD.

The prevalence of respiratory symptoms and LLN-AO in monozygotic and dizygotic twins was similar, whereas a higher prevalence of FR-AO was observed in dizygotic twins. A random twin population can be considered representative of the general population with regards to lung function. Studies have shown that lung function data from twin individuals display the same pattern as data from singleton individuals [32, 33]. A significantly lower prevalence of overweight and obesity was observed in individuals with airway obstruction compared with healthy individuals, which could be explained by the significantly higher proportion of current smokers among these individuals. Furthermore, this would explain the lower prevalence of overweight individuals in the LLN-AO group, as the prevalence of current smokers is higher than is in the fixed ratio-only group.

This study has a number of strengths. First, we included individuals from a very large nationwide population with an age span of 40-80 years. Second, compared to similar studies, this is the largest study with both questionnaire and spirometry data. Third, we have recorded the spirometry using the best available ultrasonic flowmeter with bespoke software, we used the comprehensive GLI-2012 reference values and followed the latest recommendations from ATS/ERS for epidemiological studies. Last, we performed sensitivity analyses to test the robustness of our data and to enable comparison for current and future studies.

A limitation of this study is that we only obtained prebronchodilator spirometry and thereby introduced a small risk of overestimating the presence of airway obstruction, which according to GOLD guidelines should be based on postbronchodilator spirometry [34]. However, we excluded all individuals with self-reported physician-diagnosed asthma, which has been shown to reduce the risk of overestimation [35] and any overestimation will affect both definitions of airway obstruction. Another limitation is low response rate among the MIDT cohort. This has previously been explained by three possible factors: as subjects in the MIDT cohort were younger, a higher proportion of them were still in their active work life; 2) they had to travel to one of the three examination facilities, meaning a longer journey for those living far away from the major cities; and 3) they have not been approached as often as those from the MADT follow-up study [23]. Furthermore, in a cross-sectional study, it is not possible to predict outcomes based on the different spirometric criteria.

\section{Conclusion}

In this large, nationwide population study of adults aged $40-80$ years, we found that the use of the fixed ratio criterion for $\mathrm{FEV} 1 / \mathrm{FVC}$ in diagnosing airflow obstruction resulted in a higher prevalence of airway obstruction as opposed to the LLN criterion and that the difference increased with age. The prevalence of respiratory symptoms was significantly increased among individuals with both LLN-AO and FR-AO compared with those with FR-AO only. A significantly higher proportion of those with mild to moderate airway obstruction have respiratory symptoms when graded according to ATS/ERS guidelines compared with GOLD guidelines.

\section{References}

1 World Health Organization (WHO). World Health Statistics 2008. Geneva, WHO, 2008.

2 Vogelmeier CF, Criner GJ, Martinez FJ, et al. Global strategy for the diagnosis, management and prevention of chronic obstructive lung disease 2017 report: GOLD executive summary. Respirology 2017; 22: 575-601.

3 Swanney MP, Ruppel G, Enright PL, et al. Using the lower limit of normal for the FEV1/FVC ratio reduces the misclassification of airway obstruction. Thorax 2008; 63: 1046-1051.

4 Viegi G, Pedreschi M, Pistelli F, et al. Prevalence of airways obstruction in a general population: European Respiratory Society vs American Thoracic Society definition. Chest 2000; 117: Suppl. 2, 339S-345S.

5 Celli BR, Halbert RJ, Isonaka S, et al. Population impact of different definitions of airway obstruction. Eur Respir J 2003; 22: 268-273.

6 Culver BH. Interpretation of spirometry: we can do better than the GOLD standard. Respir Care 2006; 51 719-721.

7 Schermer TRJ, Quanjer PH. COPD screening in primary care: who is sick? Prim Care Respir J 2007; 16: 49-53.

8 Miller MR, Pedersen OF, Dirksen A. A new staging strategy for chronic obstructive pulmonary disease. Int $J$ Chron Obstruct Pulmon Dis 2007; 2: 657-663. 
9 Güder G, Brenner S, Angermann CE, et al. GOLD or lower limit of normal definition? A comparison with expert-based diagnosis of chronic obstructive pulmonary disease in a prospective cohort-study. Respir Res 2012; 13: 13.

10 Miller MR, Levy ML. Chronic obstructive pulmonary disease: missed diagnosis versus misdiagnosis. BMJ 2015; 351: h3021.

11 van Dijk W, Tan W, Li P, et al. Clinical relevance of fixed ratio $v s$ lower limit of normal of FEV1/FVC in COPD: patient-reported outcomes from the CanCOLD cohort. Ann Fam Med 2015; 13: 41-48.

12 Han J, Dai L, Zhong N, et al. Breathlessness or health status in chronic obstructive pulmonary disease: the impact of different definitions. COPD 2015; 13: 115-125.

13 Lange P, Marott JL, Vestbo J, et al. Prediction of the clinical course of chronic obstructive pulmonary disease, using the new GOLD classification: a study of the general population. Am J Respir Crit Care Med 2012; 186 975-981.

14 Pellegrino R, Viegi G, Brusasco V, et al. Interpretative strategies for lung function tests. Eur Respir J 2005; 26: 948-968.

15 Quanjer PH, Stanojevic S, Cole TJ, et al. Multi-ethnic reference values for spirometry for the 3-95-yr age range: the Global Lung Function 2012 equations. Eur Respir J 2012; 40: 1324-1343.

16 Waked M, Khayat G, Salameh P. Chronic obstructive pulmonary disease prevalence in Lebanon: a cross-sectional descriptive study. Clin Epidemiol 2011; 3: 315-323.

17 Vanfleteren LE, Franssen FM, Wesseling G, et al. The prevalence of chronic obstructive pulmonary disease in Maastricht, the Netherlands. Respir Med 2012; 106: 871-874.

18 Mohamed Hoesein FAA, Zanen P, Lammers J-WJ. Lower limit of normal or FEV1/FVC $<0.70$ in diagnosing COPD: an evidence-based review. Respir Med 2011; 105: 907-915.

19 Çolak Y, Løkke A, Marott JL, et al. Impact of diagnostic criteria on the prevalence of COPD. Clin Respir J 2013; 7: 297-303.

20 Karrasch S, Brüske I, Smith MP, et al. What is the impact of different spirometric criteria on the prevalence of spirometrically defined COPD and its comorbidities? Results from the population-based KORA study. Int J Chron Obstruct Pulmon Dis 2016; 11: 1881-1894.

21 Borlée F, Yzermans CJ, Krop E, et al. Spirometry, questionnaire and electronic medical record based COPD in a population survey: comparing prevalence, level of agreement and associations with potential risk factors. PLoS One 2017; 12: e0171494.

22 Casas Herrera A, Montes de Oca M, López Varela MV, et al. COPD underdiagnosis and misdiagnosis in a high-risk primary care population in four Latin American countries. a key to enhance disease diagnosis: the PUMA study. PLoS One 2016; 11: e0152266.

23 Skytthe A, Christiansen L, Kyvik KO, et al. The Danish Twin Registry: linking surveys, national registers, and biological information. Twin Res Hum Genet 2013; 16: 104-111.

24 Miller MR, Hankinson J, Brusasco V, et al. Standardisation of spirometry. Eur Respir J 2005; 26: 319-338.

25 Quanjer PH, Pretto JJ, Brazzale DJ, et al. Grading the severity of airways obstruction: new wine in new bottles. Eur Respir J 2014; 43: 505-512.

26 Läkemedelsverket. Kroniskt Obstruktiv Lungsjukdom (KOL) - Behandlingsrekommendation. [Chronic Obstructive Pulmonary Disease (COPD) - Treatment Recommendation.] Läkemedelsverket 2015; 3: 1-15.

27 Christiansen L, Frederiksen H, Schousboe K, et al. Age- and sex-differences in the validity of questionnaire-based zygosity in twins. Twin Res 2003; 6: 275-278.

28 Kourlaba G, Hillas G, Vassilakopoulos T, et al. The disease burden of chronic obstructive pulmonary disease in Greece. Int I Chron Obstruct Pulmon Dis 2016; 11: 2179-2189.

29 Hardie JA, Buist AS, Vollmer WM, et al. Risk of over-diagnosis of COPD in asymptomatic elderly never-smokers. Eur Respir J 2002; 20: 1117-1122.

30 Vollmer WM, Gíslason T, Burney P, et al. Comparison of spirometry criteria for the diagnosis of COPD: results from the BOLD study. Eur Respir J 2009; 34: 588-597.

31 Medbø A, Melbye $\mathrm{H}$. What role may symptoms play in the diagnosis of airflow limitation? A study in an elderly population. Scand J Prim Health Care 2008; 26: 92-98.

32 Yu Y, Kumar R, Venners S, et al. Age and gender specific lung function predictive equations provide similar predictions for both a twin population and a general population from age 6 through adolescence. Pediatr Pulmonol 2007; 42: 631-639.

33 Højland AT, Titlestad IL, Kyvik KO, et al. Can the national reference equations for FEVı and FVC deduced from a non-twin population be used on Danish twins. Eur Respir J 2004; 24: Suppl. 48, 1832.

34 Johannessen A, Omenaas ER, Bakke PS. Implications of reversibility testing on prevalence and risk factors for chronic obstructive pulmonary disease: a community study. Thorax 2005; 60: 842-847.

35 de Marco R, Accordini S, Cerveri I, et al. An international survey of chronic obstructive pulmonary disease in young adults according to GOLD stages. Thorax 2004; 59: 120-125. 